\title{
Deertechz
}

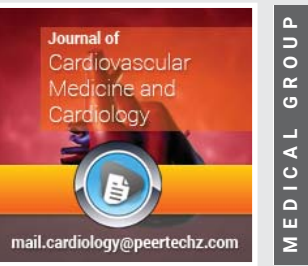

Research Article

\section{Circulatory pulmonary artery denervation in patients with severe pulmonary hypertension undergoing combined mitral valve surgery and procedure Maze IV}

\section{Babokin Vadim Egorovich ${ }^{1}$, Trofimov Nikolai}

Alexandrovich ${ }^{2 *}$, Medvedev Aleksander Pavlovich ${ }^{3}$, Nikolskiy Alexander Viktorovich ${ }^{4}$, Dragunov Andrey Gennadievich ${ }^{5}$, Egorov Dmitrii Vladimirovich ${ }^{6}$ and Babokina Sofia Vadimovna ${ }^{7}$

'Doctor of Medical Sciences, professor, cardiovascular surgeon. Chair of Hospital Surgery, Bashkir State Medical University, 3 Lenin str., 450008 Ufa, Russia. Division of Cardiovascular Surgery, Central Clinical Hospital of the Russian Academy of Sciences, Litovskij bulvar, 117593, 1A, Moscow, Russia ${ }^{2}$ Candidate of Medical Sciences, cardiovascular surgeon. Chair of Hospital Surgery, Privolzhsky Research Medical University, 10 Minin and Pozharsky square, bld 1, 603005 Nizhny Novgorod, Russia ${ }^{3}$ Doctor of Medical Sciences, Professor, Head of the Department of Hospital Surgery, cardiovascular surgeon. Chair of Hospital Surgery, Privolzhsky Research Medical University, 10 Minin and Pozharsky square, bld 1,603005, Nizhny Novgorod, Russia

${ }^{4}$ Candidate of Medical Sciences, cardiovascular surgeon. Chair of Hospital Surgery, Privolzhsky Research Medical University, 10 Minin and Pozharsky square, bld 1, 603005, Nizhny Novgorod, Russia ${ }^{5}$ Candidate of Medical Sciences, Head of the Department of Cardiac Surgery, cardiovascular surgeon. Republic Cardiac Dispensary, 29 Gladkov Str, 428020, Cheboksary, Russia

${ }^{6}$ Cardiovascular surgeon of the Department of Cardiac Surgery, Republic Cardiac Dispensary, 29 Gladkov Str, 428020, Cheboksary, Russia

${ }^{7}$ General medicine student. Sechenov University, 8-2 Trubetskaya str, 119991, Moscow, Russia
Received: 12 May, 2020

Accepted: 23 May, 2020

Published: 25 May, 2020

*Corresponding author: Trofimov Nikolai Alexandrovich, Candidate of Medical Sciences, cardiovascular surgeon. Chair of Hospital Surgery, Privolzhsky Research Medical University, 10 Minin and Pozharsky square, bld 1, 603005 Nizhny Novgorod, Russia,

E-mail: nikolai.trofimov@mail.ru

Keywords: Secondary pulmonary hypertension; Pulmonary arteries denervation; Mitral valve disease; Atrial fibrillation

https://www.peertechz.com

Check for updates 


\section{Abstract}

Background: The aim of this study was to evaluate the impact of sympathetic denervation of the pulmonary trunk and main pulmonary arteries on outcomes of surgical treatment in patients with mitral valve dysfunction, complicated by atrial fibrillation (AF) and severe Pulmonary Hypertension (PH).

Method: Between September 2013 and July 2019, 140 patients with mitral valve dysfunction, concomitant AF and severe PH (mean pulmonary arterial pressure, MPAP, greater than $40 \mathrm{mmHg}$ ) who underwent cardiac surgery were analyzed. In the Denervation group, 51 patients underwent mitral valve surgery, biatrial Maze IV procedure and radiofrequency denervation of trunk and both main pulmonary arteries (pulmonary artery denervation, PADN). In the control group, 89 patients underwent the same surgery stages without PADN procedure.

Results: Circular pulmonary artery denervation (PADN) contributes to a significant reduction in secondary PH ( $p=0.018)$, reverse remodeling of the heart chambers, in particular the left atrium $(p=0.01)$, is an effective and safe method, and improves the results of the Maze IV procedure ( $p=0.022)$ due to the sinus rhythm restoration, in patients with mitral valve dysfunction, complicated by $\mathrm{AF}$ and $\mathrm{PH}$.

Conclusions: Circulatory PADN additional to mitral valve surgery and Maze procedure represents a safe and effective treatment method for patients with mitral valve dysfunction, complicated by $\mathrm{AF}$ and severe $\mathrm{PH}$. It is necessary to continue the study of this technique involving a larger number of patients, to analyze long-term outcomes and use this technique in patients with non-valvular causes of secondary $\mathrm{PH}$.

\section{Abbreviations}

AF: Atrial Fibrillation; LADs: Left Atrium Anterior-Posterior Diameter in Systole; LVEDV: Left Ventricular End-Diastolic Volume; LVEF: Left Ventricular Ejection Fraction; LVESV: Left Ventricular End-Systolic Volume; LVIDd: Left Ventricular Internal Diameter in diastole; LVIDs: Left Ventricular Internal Diameter in Systole; MPAP: Mean Pulmonary Arterial Pressure; PADN: Pulmonary Artery Denervation; PH: Pulmonary Hypertension; RADs: Right Atrium Anterior-posterior Diameter in Systole; RVD: Right Ventricular Basal Diameter; TVI: Tricuspid Valve Insufficiency

\section{Introduction}

During the natural course of the mitral valve defects that reach $9.3 \%$ of the population [1], there are various structural changes that require the use of an individual approach in each case. The main reasons are the etiological factors, the occurrence of $\mathrm{AF}$, the growth of secondary $\mathrm{PH}$, dilation of the heart chambers, comorbid pathology, etc. $[2,3]$. The growth of secondary $\mathrm{PH}$ on the background of the progression of mitral heart disease, contributes to the right heart overload, occurrence of tricuspid valve insufficiency and, as a consequence, poor prognosis, premature death and reduced quality of life of this category of patients [4].

Effective treatment of severe $\mathrm{PH}$ is the stumbling block of modern medicine. Medication drugs are still expensive and not at all cases allow enough to reduce $\mathrm{PH}$ [5].

The first methods for the surgical correction of PH were proposed by S.L. Chen in 2013, which proposed to perform pulmonary denervation using an endovascular catheter and achieved a significant reduction in pressure in the pulmonary artery [6]. The feasibility of surgical denervation of the sympathetic plexuses in the pulmonary arteries was also demonstrated in the works of S. Briongos Figuero et al., who showed that a severe of secondary $\mathrm{PH}$ in the preoperative period closely correlates with high persistent $\mathrm{PH}$ in the postoperative period, even after correction of mitral valve disease (odds ratio $1.761 ; \mathrm{p}=0.03$ ) [7]. Later, methods of surgical treatment of $\mathrm{PH}$ under extracorporeal circulation with simultaneous correction of valvular heart disease were presented, consisting in epicardial ablation of the anterior wall of the trunk and main pulmonary arteries using a monopolar stick electrode [8] and also another method of circular ablation of the trunk and main pulmonary arteries using a bipolar destructor were described [9]. This study evaluates the impact of sympathetic denervation of the pulmonary trunk and main pulmonary arteries on outcomes of surgical treatment in patients with mitral valve dysfunction, complicated by $\mathrm{AF}$ and severe $\mathrm{PH}$.

\section{Material and methods}

\section{Patients}

The analysis of surgical treatment of 140 patients with mitral valve disease, concomitant $\mathrm{AF}$ and severe $\mathrm{PH}$ has been carried out. Surgical intervention in these patients consisted in the correction of a mitral valve disease (replacement or repair). Due to the arrhythmic history, biatrial radiofrequency ablation was performed according to the Maze IV scheme using isolator synergy bipolar clamps under the control of transmurality. In the Denervation group, 51 patients ( 46 patients with severe mitral stenosis and 5 with 4 th degree mitral valve insufficiency) underwent mitral valve surgery ( 47 valve replacement, 4 valve repair) plus biatrial Maze IV procedure and PADN. The criteria for inclusion in the denervation group were the presence of a mitral valve disease, $\mathrm{AF}$, severe $\mathrm{PH}$, absence of significant coronary artery lesions. The study has been approved by local ethical committee. All the studied patients before the operation, without fail, were informed about the upcoming additional procedure PADN, which was planned to be performed with the main stage of surgical correction, signed informed voluntary, according to the principles of clinical practice (Good Clinical Practice - GCP), in accordance with the Helsinki Declaration. In the control group, 89 patients, who also had severe mitral valve dysfunction, underwent the same surgery stages without PADN procedure.

\section{Surgical technique}

Denervation of the trunk and orifices of bilateral pulmonary arteries was performed by circular line with a Isolator Synergy Bipolar radiofrequency Clamps. On beating heart with the concomitant use of cardiopulmonary bypass, bifurcations of the pulmonary trunk were identified, followed by the application 
of 2 circular lines to the distal region of the pulmonary trunk, 3 appliques each (Figure 1). Then, the orifices of bilateral pulmonary arteries were isolated followed by the application of similar ablation lines. The orifice of the right pulmonary artery was isolated by the right of the aorta, in the projection of the transverse sinus of the heart. Procedure in the final represents 6 ablation lines, 2 at the level of the distal part of the pulmonary trunk and 2 at the orifices of bilateral pulmonary arteries (Figure 2). Myocardial protection with antegrade cardioplegia was performed into the aortic root and, after the cardiac arrest, the main stage of the operation was performed - correction of valvular heart dysfunction and the Maze IV procedure.

\section{Follow-Up}

At intensive care unit and before discharge the monitoring of echocardiography indicators was carried out for all patients. Postoperative management of patients of the Denervation group did not differ from the management of patients in the control group. All patients were followed prospectively with annual visits. The dynamics of the reduction of $\mathrm{PH}$ was controlled by the results of transthoracic echocardiography in $3,6,12,24$ months after surgery.

\section{Statistical analyses}

Statistical processing of the results was carried out in the program "SPSS Statistics 26". Quantitative data were given as mean and standard deviation ( $M \pm \sigma$ ), with rank values or incorrect distribution, as median and upper and lower quartiles

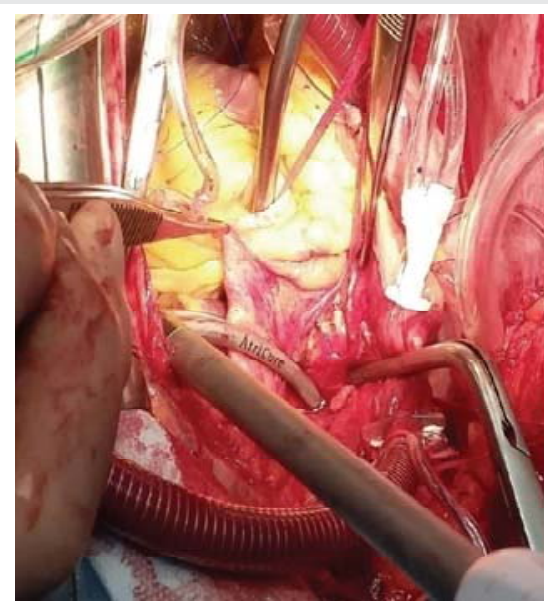

Figure 1: Pulmonary trunk ablation

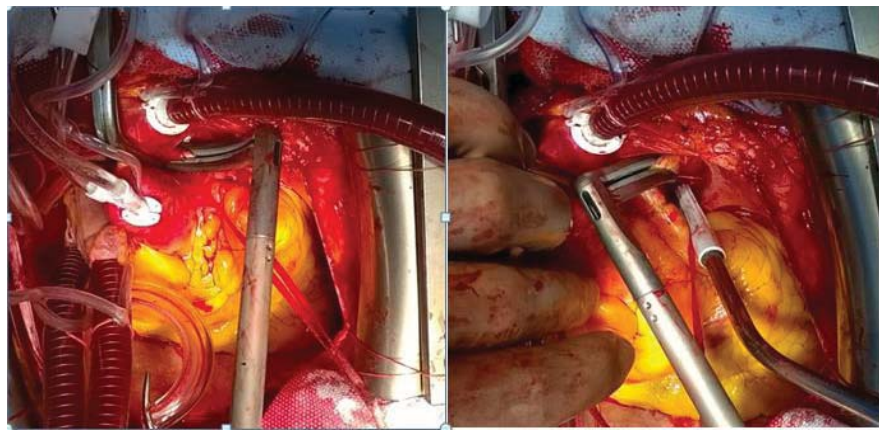

Figure 2: The orifices of bilateral pulmonary arteries ablation.
(Me; $\left.\left\{\mathrm{Q} 1-\mathrm{O}_{3}\right\}\right)$. Due to the irregular nature of the distribution, for rank and quantitative data, the statistical significance of the differences was estimated by the Mann-Whitney test $\left(\mathrm{p}_{\mathrm{m}-}\right.$ u). For qualitative data (relative values), the differences were evaluated by the chi-square test $\left(\chi^{2}\right)$. When the number of observations in at least one of the values of Table 1 was less than 5, the calculation was carried out using Fisher's exact test. The probability value ( $\mathrm{p}$ ) was considered acceptable at $\mathrm{p}<0.05$

\section{Results}

Patients of the Denervation group $(n=51)$ and Control ( $n=89$ ) were comparable in terms of the main clinical and demographic values (Table 2). Intergroup differences characterize Denervation group as more severe (by age, EuroSCORE II, left ventricle and right chambers dilation, LVEF, PH degree). Despite the significant difference in the age of the compared groups of patients, the influence of this factor is estimated as small, and the PASP value is important [10].

Mean overall PADN procedure time was $5,5 \pm 1,5$ minutes. Mean overall aortic cross-clamp time was $85,2 \pm 26,6$ minutes, cardiopulmonary bypass time was 114,1 \pm 33,4 minutes. Patients stay in the intensive care unit for $2.4 \pm 3.1$ days. The mortality was by one patient in each group, and was caused by progressive acute heart failure in the intrahospital period specific complications associated with the proposed method of surgical treatment of severe $\mathrm{PH}$ were not observed.

Positive dynamics of echocardiographic parameters in the postoperative period was observed in all patients (Table 1). The table results demonstrate reverse remodeling of heart chambers, improvement of LVEF, reduction in $\mathrm{PH}$ in the Denervation group. On initially worst values of the Denervation group, the comparable results were achieved with the control group that had a significant difference in echocardiographic values and patient age.

The changes of mean values of PAP in research groups demonstrated at Figure 3. It demonstrates advantages of combined approach to correction of mitral valve dysfunction in patients with $\mathrm{AF}$ and $\mathrm{PH}$. PADN performed on Denervation group patients with higher $\mathrm{PH}$, helps to achieve significantly lower MPAP in pulmonary circulation after 3 months in comparison of control group.

Improvement of echocardiography dimensions of left atrium demonstrated at Figure 4. The presented time curve demonstrates the better results of reverse remodeling of the left atrium in the denervation group already 12 months after surgery.

The final result of the complex remodeling of the heart is the better maintenance of sinus rhythm in the postoperative period. Surgical treatment of AF, that was carried out in patients of both groups, demonstrates the results presented in Figure 5 (data are presented in \% of patients with sinus rhythm in each denervation group). The presented data demonstrate the better indicators of sinus rhythm maintenance in the group, where the correction of valvular pathology and surgical treatment of AF was supplemented with pulmonary denervation. An integrated 
Table 1: Postoperative changes of tracked echocardiographic data

\begin{tabular}{|c|c|c|c|c|}
\hline & & $\begin{array}{l}\text { Denervation group } \\
\qquad(\mathrm{n}=51)\end{array}$ & $\begin{array}{l}\text { Control group } \\
\qquad(n=89)\end{array}$ & $p$ Value \\
\hline \multirow{2}{*}{ TVI degree } & before surgery & $2(1-3)$ & $2(2-3)$ & 0.095 \\
\hline & after 24 months & $0(0-0)$ & $1(1-1)$ & $<0.001$ \\
\hline \multirow{2}{*}{ NYHA class } & before surgery & $3(3-4)$ & $3(3-4)$ & 0.058 \\
\hline & after 24 months & $2(2-2)$ & $2(2-3)$ & 0.023 \\
\hline \multirow{2}{*}{ LVIDd, cm } & before surgery & $5.6(5.4-6.4)$ & $5.5(5.2-5.7)$ & 0.014 \\
\hline & after 24 months & $4.6(4.5-5.3)$ & $4.8(4.6-5.1)$ & 0.896 \\
\hline \multirow{2}{*}{ LVIDs, cm } & before surgery & $4(3.8-4.8)$ & $3.8(3.6-4.1)$ & $<0.001$ \\
\hline & after 24 months & $3.2(3-3.6)$ & $3.3(3.1-3.7)$ & 0.625 \\
\hline \multirow{2}{*}{ LVEDV, cm } & before surgery & $153.66(135.34-208.52)$ & $143.2(130.4-160.04)$ & 0.016 \\
\hline & after 24 months & 97.34 (93.8-135.34) & $105.85(97.34-123.81)$ & 0.858 \\
\hline \multirow{2}{*}{ LVESV, cm } & before surgery & 70 (61.95-107.52) & $61.95(54.43-71.2)$ & $<0.001$ \\
\hline & after 24 months & $42.55(35-54.43)$ & $44.13(36.46-57.71)$ & 0.691 \\
\hline \multirow{2}{*}{ LFEV, \% } & before surgery & $52.18 \%$ & $56.26 \%$ & $<0.001$ \\
\hline & after 24 months & $58.2 \%$ & $57.94 \%$ & 0.857 \\
\hline \multirow{2}{*}{$\mathrm{RVD}, \mathrm{cm}$} & before surgery & $3.6(3.4-4)$ & $3.4(3.2-3.7)$ & 0.003 \\
\hline & after 24 months & $2.9(2.8-3.2)$ & $3(2.9-3.1)$ & 0.156 \\
\hline \multirow[t]{2}{*}{ LADs, cm } & before surgery & $5.5(5.3-5.7)$ & $5.4(5.2-5.6)$ & 0.600 \\
\hline & after 24 months & $4.1(3.8-4.3)$ & $4.3(4-4.6)$ & 0.010 \\
\hline \multirow{2}{*}{ RADs, cm } & before surgery & $5.8(5.6-6)$ & $5.6(5.2-5.9)$ & 0.095 \\
\hline & after 24 months & $4.5(4.4-5)$ & $5(4.4-5.3)$ & 0.073 \\
\hline \multirow{2}{*}{ MPAP, mmHg } & before surgery & $48(45-60)$ & $46(44-50)$ & 0.018 \\
\hline & after 24 months & $23(21-28)$ & $26(23.5-29.4)$ & 0.519 \\
\hline \multirow{2}{*}{$A F, \%$} & before surgery & $100 \%$ & $100 \%$ & $>0.05$ \\
\hline & after 24 months & $16 \%$ & $34 \%$ & 0.022 \\
\hline
\end{tabular}

TVI: Tricuspid Valve Insufficiency; LVIDd: Left Ventricular Internal Diameter in diastole; LVIDs: Left Ventricular Internal Diameter in Systole; LVEDV: Left Ventricular EndDiastolic Volume; LVEF: Left Ventricular Ejection Fraction; RVD: Right Ventricular Basal Diameter; LADs: Left Atrium Anterior-Posterior Diameter in Systole; MPAP: Mean Pulmonary Arterial Pressure

Table 2: Preoperative Patients Characteristics $(n=140)$.

\begin{tabular}{|c|c|c|c|}
\hline & $\begin{array}{c}\text { Denervation group } \\
(\mathrm{n}=51)\end{array}$ & $\begin{array}{c}\text { Control group } \\
\quad(n=89)\end{array}$ & p Value \\
\hline Gender (male/female) & $23 / 28$ & $28 / 61$ & 0.108 \\
\hline Age at operation, years & $59.43 \pm 5.18$ & $55.81 \pm 8.26$ & 0.005 \\
\hline \multicolumn{4}{|l|}{ Cause of mitral valve disease } \\
\hline Rheumatic fever & $74 \%$ & $87 \%$ & 0.072 \\
\hline Infective endocarditis & $20 \%$ & $9 \%$ & 0.096 \\
\hline Degenerative & $6 \%$ & $4 \%$ & 0.657 \\
\hline \multicolumn{4}{|l|}{ Type of AF } \\
\hline Long-term persistent & $86 \%$ & $84 \%$ & 0.751 \\
\hline Persistent & $8 \%$ & $2 \%$ & 0.117 \\
\hline Paroxysmal & $6 \%$ & $14 \%$ & 0.164 \\
\hline Arrhythmia history, years & $2.63 \pm 1.37$ & $2.74 \pm 1.74$ & 0.688 \\
\hline Atrial flutter & $14 \%$ & $20 \%$ & 0.337 \\
\hline Carotid stenosis $>50 \%$ & $18 \%$ & $17 \%$ & 0.905 \\
\hline Past medical history of a stroke & $8 \%$ & $8 \%$ & 0.996 \\
\hline EuroSCORE & $5.71 \pm 2.27$ & $4.65 \pm 1.87$ & 0.004 \\
\hline Cardiopulmonary bypass time, $\min$ & $114.1 \pm 33.44$ & $119.47 \pm 49.52$ & 0.511 \\
\hline Aortic cross-clamp time, min & $85.2 \pm 26.64$ & $90.42 \pm 32.45$ & 0.359 \\
\hline TVI, degree & $1.94 \pm 0.81$ & $2.18 \pm 0.81$ & 0.095 \\
\hline NYHA class & $3.43 \pm 0.5$ & $3.27 \pm 0.47$ & 0.058 \\
\hline LVIDd, cm & $5,84 \pm 0,6$ & $5,59 \pm 0,55$ & 0.014 \\
\hline LVIDs, cm & $4,25 \pm 0,54$ & $3,92 \pm 0,52$ & $<0.001$ \\
\hline LVEDV, $\mathrm{cm}$ & $171.47 \pm 41.33$ & $154.99 \pm 36.59$ & 0.016 \\
\hline LVESV, $\mathrm{cm}$ & $82.52 \pm 25.26$ & $68.45 \pm 22.52$ & $<0.001$ \\
\hline LVEF & $52.45 \%$ & $56.36 \%$ & $<0.001$ \\
\hline
\end{tabular}

\begin{tabular}{|c|c|c|c|}
\hline RVD, $c m$ & $3.63 \pm 0.33$ & $3.46 \pm 0.3$ & 0.003 \\
\hline LADs, cm & $5.48 \pm 0.35$ & $5.42 \pm 0.67$ & 0.600 \\
\hline RADs, cm & $5.71 \pm 0.41$ & $5.56 \pm 0.57$ & 0.095 \\
\hline MPAP, mmHg & $50.02 \pm 8.67$ & $46.87 \pm 6.78$ & 0.018 \\
\hline
\end{tabular}

TVI: Tricuspid Valve Insufficiency; LVIDd: Left Ventricular Internal Diameter in diastole; LVIDs: Left Ventricular Internal Diameter in Systole; LVEDV: Left Ventricular End-Diastolic Volume; LVEF: Left Ventricular Ejection Fraction; RVD: Right Ventricular Basal Diameter; LADs: Left Atrium Anterior-Posterior Diameter in Systole; MPAP: Mean Pulmonary Arterial Pressure

approach in the Denervation group allows, after 3 months, to achieve the preservation of sinus rhythm at the level of $99.6 \%$, while in the control group this indicator is at the level of $80 \%$ $(\mathrm{p}=0.008)$.

\section{Conclusion}

The prevalence of $\mathrm{AF}$ is one of the highest among heart rate disturbance, reaches $2 \%$ in population and has a tendency to increase over the past 10 years [11]. The arrhythmia tightly correlates with up to $24.6 \%$ of valvular heart disease patients, decreases cardiac surgery effectiveness and quality of life, increases risk of thromboembolic events, progression of heart failure, and, as an entire result, increases mortality [12-14]. Mitral valve dysfunction due to the natural course, provokes left atrial dilatation, and on base of structural alterations and electrical blocks the aberrant re-entry is forming [15]. Thus valve surgery is the high-priority goal to successful AF treatment. But even adequate correction of the mitral valve pathology in patients with preoperative AF leads to the sinus rhythm restoration only in $8.5-20 \%$, and additional surgical 
intervention is required $[16-18]$. $\mathrm{PH}$ is defined as a mean pulmonary arterial systolic pressure greater than $25 \mathrm{mmHg}$, severe $\mathrm{PH}$ - greater than $40 \mathrm{mmHg}[19,20]$.

The presence of severe $\mathrm{PH}$ in patients with valvular pathology reduces the effectiveness of cardiac surgery, promotes a more prolonged adverse remodeling of the heart chambers and reduces the effectiveness of surgical treatment of AF. Pathological aspects of severe $\mathrm{PH}$ are caused by an imbalance between vasodilators and vasoconstrictors on the background of morphological remodeling of the vessel wall [21-23]. In 1962, Osorio J. et al, for the first time proved the existence of sympathetic plexus in the adventitia of the trunk and main pulmonary arteries, that are responsible for the spasm of pulmonary arterioles and increased pressure in the pulmonary circulation [24]. Later, this data was also confirmed in the research works of Baylen [25] and Juratsch [26].

This work represents an analysis of the results of surgical treatment of a high degree secondary $\mathrm{PH}$, by radiofrequency denervation of the distal pulmonary trunk and the orifices of bilateral pulmonary arteries under the control of transmurality. The control group is identical to the cohort of patients, where correction of mitral valve dysfunction and AF is also performed, but without correction of severe $\mathrm{PH}$. Despite the short observation time and a small sample of patients, the

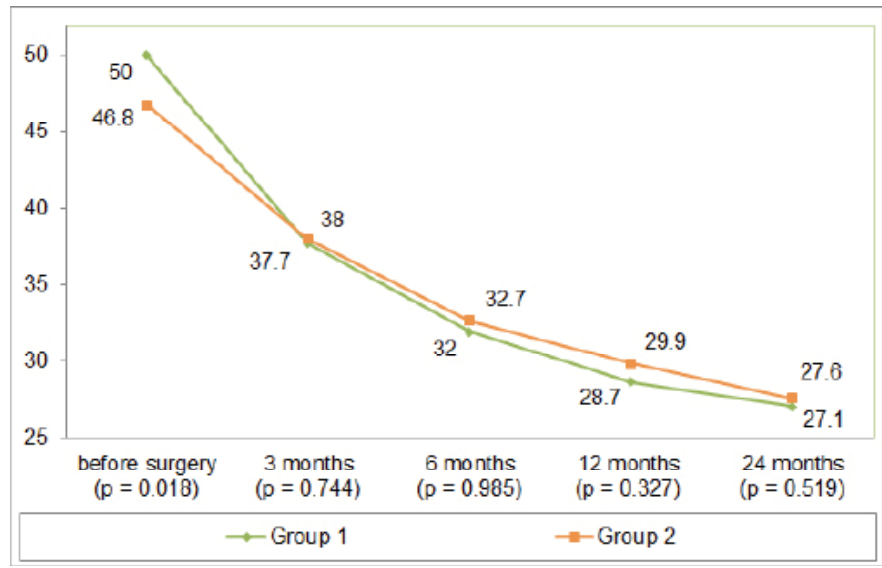

Figure 3: MPAP changes in research groups.

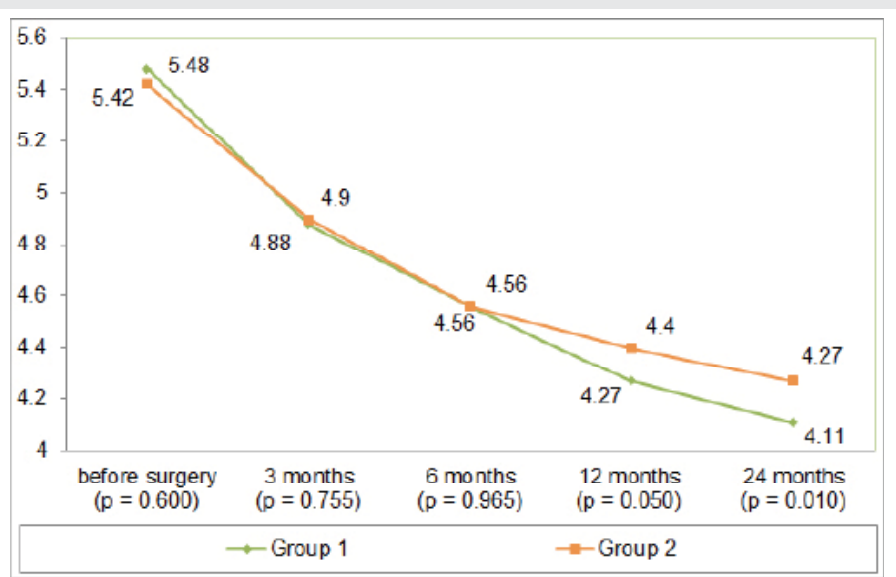

Figure 4: Improvement of echocardiography dimensions of left atrium.

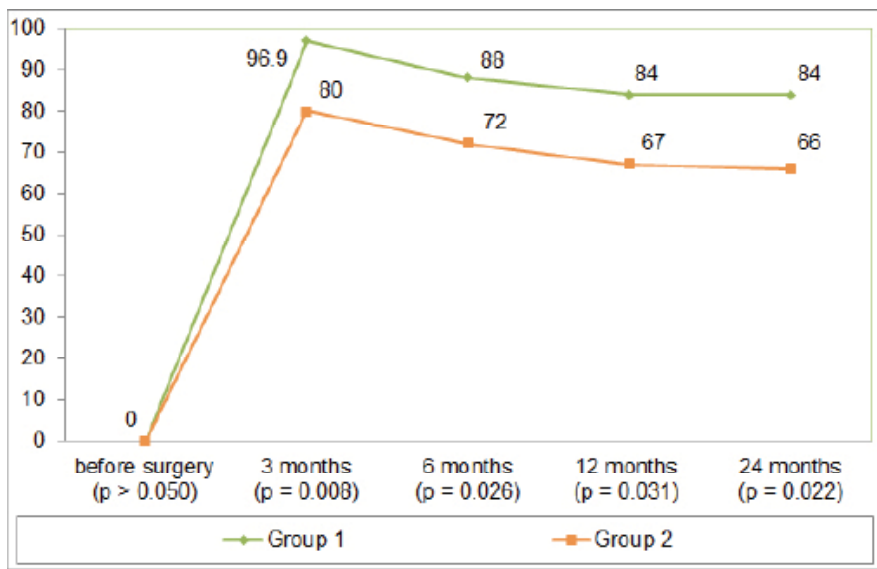

Figure 5: The maintenance of sinus rhythm in the studied groups; statistical significance is calculated by chi-square test.

presented results demonstrate significantly better results of cardiac chamber remodeling, improvement in ejection fraction, reduction in $\mathrm{PH}$, and better maintenance of sinus rhythm in the denervation group.

Elimination of severe $\mathrm{PH}$ in this case is caused not only by correction of mitral valve dysfunction, but also by denervation of sympathetic nerve fibers located in the trunk and orifices of bilateral pulmonary arteries, which leads to spasm elimination of small arteries and arterioles, vasodilation and, as a result, increasing in the capacity of the pulmonary circulation and pressure reducing in the left atrial. The proposed method is simple in technical performance, does not affect the time of myocardial ischemia, since it is performed on the on-pump beating-heart, and in our cases was not accompanied by any complications. The mean denervation time was 5-7 minutes.

As a result of this work, the effectiveness, safety, and practical significance of the proposed methodology were demonstrated. In addition, when the Maze IV procedure is performed simultaneously, the same Isolator Synergy Bipolar Clamps is used, both for the surgical treatment of AF and for the correction of severe $\mathrm{PH}$. The use of bipolar clamping allows circular denervation to be performed, which, in our opinion, is more effective in comparison with the ablation technique of only the anterior wall of the pulmonary trunk and the orifices of bilateral pulmonary arteries.

Based on the conducted research, it can be concluded that circular radiofrequency denervation of the trunk and orifices of bilateral pulmonary arteries, using a destructor clamp, is an effective and safe method, and also improves the results of the Maze IV procedure due to better maintenance of sinus rhythm in patients with mitral valve dysfunction complicated by $\mathrm{AF}$ and severe PH. It is necessary to continue the study of this technique with the involvement of a larger number of patients, the analysis of long-term results and the use of this technique in patients with non-valvular causes of secondary $\mathrm{PH}$.

\section{References}

1. Rostagno C (2019) Heart valve disease in elderly. World J Cardiol 11: 71-83. Link: https://bit.ly/36wi10s

Citation: Babokin VE, Trofimov NA, Medvedev AP, Nikolskiy AV, Dragunov AG, et al. (2020) Circulatory pulmonary artery denervation in patients with severe pulmonary hypertension undergoing combined mitral valve surgery and procedure Maze IV. J Cardiovasc Med Cardiol 7(2): 146-151 
2. Trofimov NA, Medvedev AP, Babokin VE, Demarin OI, Zhamlikhanov NK, et al. (2016) Surgical Treatment of Complex Arrhythmias in Patients with NonIschemic Mitral Insufficiency. Almanac of Clinical Medicine 64-73. Link: https://bit.ly/3cSpvgW

3. Babokin VE, Rogovskaya YV, Shipulin VM, Batalov RE, Popov SV (2015) Morphology of electrophysiological disorders of myocardium in postinfarction aneurysm and ventricular tachycardia. Russian Journal of Cardiology 11: 1822. Link: https://bit.ly/3edm3xA

4. Zheleznev SI, Demidov DP, Afanasiev AV, Nazarov VM, Demin II, et al. (2016) Radiofrequency Denervation of Pulmonary Artery in Surgery of Dysplastic Mitral Valve Defects with Severe Pulmonary Hypertension. Russian Journal of Cardiology 70-72. Link: https://bit.ly/2ZxAFUu

5. Guazzi M, Vitelli A, Labate V, Arena R (2012) Treatment for pulmonary hypertension of left heart disease. Curr Treat Options Cardiovasc Med 14: 319-327. Link: https://bit.ly/3d1A40Q

6. Chen SL, Zhang FF, Xu J, Xie DJ, Zhou L, et al. (2013) Pulmonary artery denervation to treat pulmonary arterial hypertension: the single-center prospective, first-in-man PADN-1 study (first-in-man pulmonary artery denervation for treatment of pulmonary artery hypertension). J Am Coll Cardiol 62: 1092-1100. Link: https://bit.ly/3c0zNKG

7. Briongos Figuero S, Moya Mur JL, Garcia-Lledo A, Centella T, Salido L, et al (2016) Predictors of persistent pulmonary hypertension after mitral valve replacement. Heart Vessels 31: 1091-1099. Link: https://bit.ly/3bWx44T

8. Bogachev-Prokofiev AV, Zheleznev SI, Afanasyev AV, Fomenko MS, Demido DP, et al. (2019) Denervation of pulmonary artery during mitral valve surgery in patients with high pulmonary hypertension. Pulmonary Artery Denervation in Patients with Mitral Valve Defects 19: 19-25. Link: https://bit.ly/3galS8h

9. Trofimov NA, Medvedev AP, Dragunov AG, Nikolsky AV, Mizurova TN, et al (2017) Method of surgical treatment of secondary pulmonary hypertension in the case of patients having surgical correction of mitral valve pathology. Medical almanac 33-37. Link:

10. Lam CS, Borlaug BA, Kane GC, Enders FT, Rodeheffer RJ, et al. (2009) Age associated increases in pulmonary artery systolic pressure in the general population. Circulation 119: 2663-2670. Link: https://bit.ly/2WXdMrK

11. Zoni-Berisso M, Lercari F, Carazza T, Domenicucci S (2014) Epidemiology of atrial fibrillation: European perspective. Clin Epidemiol 6: 213-220. Link: https://bit.ly/3ecWfSg

12. Breithardt $\mathrm{G}$, Baumgartner $\mathrm{H}$ (2015) Valvular heart disease among non-valvular atrial fibrillation: a misnomer, in search of a new term. Eur Heart J 36: 17941797. Link: https://bit.ly/2Zrpf4N

13. Kirchhof P, Ammentorp B, Darius H, De Caterina R, Le Heuzey JY, et al. (2014) Management of atrial fibrillation in seven European countries after the publication of the 2010 ESC Guidelines on atrial fibrillation: primary results of the PREvention oF thromboemolic events--European Registry in Atrial Fibrillation (PREFER in AF). Europace 16: 6-14. Link: https://bit.ly/2ZtILgR

14. Kim JS, Lee SA, Park JB, Chee HK, Chung JW (2014) Preoperative risk factor analysis of postoperative stroke after Cox-maze procedure with mitral valve repair. BMC Cardiovasc Disord 14: 116. Link: https://bit.ly/3geGpsc

15. Cox JL (2003) Atrial fibrillation I: a new classification system. J Thorac Cardiovasc Surg 126: 1686-1692. Link: https://bit.ly/3cX2tFN

16. Kirchhof P, Benussi S, Kotecha D, Ahlsson A, Atar D, et al. (2016) 2016 ESC Guidelines for the management of atrial fibrillation developed in collaboration with EACTS. Eur J Cardiothorac Surg 37: 2893-2962. Link: https://bit.ly/2yrWSz7
17. Babokin V, Trofimov N (2020) Prevention of atrial fibrillation recurrence after the Maze IV procedure. Ann Thorac Surg 109: 1624-1625. Link: https://bit.ly/36p33JN

18. Gillinov AM, Gelijns AC, Parides MK, DeRose JJ, Moskowitz AJ, et al. (2015) Surgical ablation of atrial fibrillation during mitral-valve surgery. N Engl J Med 372: 1399-1409. Link: https://bit.ly/2ZuqlqV

19. Hurdman J, Condliffe R, Elliot CA, Davies C, Hill C, et al. (2012) ASPIRE registry: assessing the Spectrum of Pulmonary hypertension Identified at a REferral centre. Eur Respir J 39: 945-955. Link: https://bit.ly/3gkdyTA

20. Bogunetsky AA, Ussov VY, Babokin VE (2014) Cardiovascular magnetic resonance with contrast agent: prognostic role in determining arrhytmogenic focus. Bulletin of Siberian Medicine 13: 98-102.

21. Rubin LJ (1997) Primary pulmonary hypertension. N Engl J Med 336: 111-117. Link: https://bit.ly/3cWua1B

22. Galie N, Manes A, Negro L, Palazzini M, Bacchi-Reggiani ML, et al. (2009) A meta-analysis of randomized controlled trials in pulmonary arterial hypertension. Eur Heart J 30: 394-403. Link: https://bit.ly/2A7Jc5N

23. Hoeper MM, Barbera JA, Channick RN, Hassoun PM, Lang IM, et al. (2009) Diagnosis, assessment, and treatment of non-pulmonary arterial hypertension pulmonary hypertension. J Am Coll Cardiol 54: 85-96. Link: https://bit.ly/3cWuhu3

24. Osorio J, Russek M (1962) Reflex changes on the pulmonary and systemic pressures elicited by stimulation of baroreceptors in the pulmonary artery. Circ Res 10: 664-667. Link: https://bit.ly/3gfHWOO

25. Baylen BG, Emmanouilides GC, Juratsch CE, Yoshida Y, French WJ, et al (1980) Main pulmonary artery distention: A potential mechanism for acute pulmonary hypertension in the human newborn infant. J Pediatr 96: 540-544. Link: https://bit.ly/2WYMSQB

26. Juratsch CE, Jengo JA, Castagna J, Laks MM (1980) Experimental pulmonary hypertension produced by surgical and chemical denervation of the pulmonary vasculature. Chest 77: 525-530. Link: https://bit.ly/3edoj8d

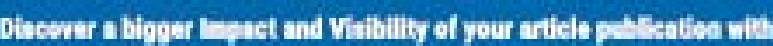
Peertechz Publications

\section{Highwghts}

- Sipnatsy putanet af ONoD

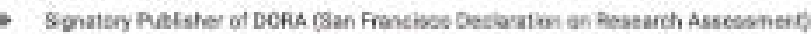

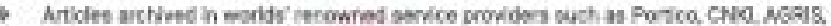

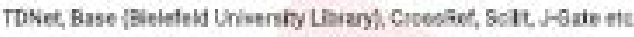

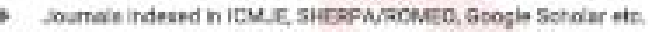

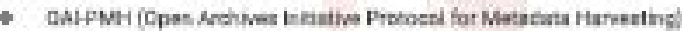

* Detbathed Eshoris Laard for nery journa

- Acturane and rapid peer review prostss

- hereasad etwotions of publishad articles through promobish

- Apayed tmelhe sor artale pitikgtion

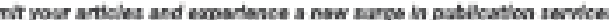

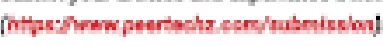

Copyright: @ 2020 Egorovich BV, et al. This is an open-access article distributed under the terms of the Creative Commons Attribution License, which permits unrestricted use, distribution, and reproduction in any medium, provided the original author and source are credited.

Citation: Babokin VE, Trofimov NA, Medvedev AP, Nikolskiy AV, Dragunov AG, et al. (2020) Circulatory pulmonary artery denervation in patients with severe pulmonary hypertension undergoing combined mitral valve surgery and procedure Maze IV. J Cardiovasc Med Cardiol 7(2): 146-151. 